\title{
Pelvic floor dysfunction in endometrial cancer patients after treatment. A literature review
}

\author{
Iakovos Theodoulidis ${ }^{1}$, Themistoklis Mikos ${ }^{1, *}$, Dimitrios Tsolakidis ${ }^{1}$, Leonidas Zepiridis ${ }^{1}$, \\ Grigoris F Grimbizis ${ }^{1}$ \\ ${ }^{1}$ First Department of Obstetrics and Gynecology, Papageorgiou General Hospital, Aristotle University of Thessaloniki, 56403 Thessaloniki, Greece \\ *Correspondence: themis.mikos@gmail.com (Themistoklis Mikos) \\ Academic Editor: Enrique Hernandez \\ Submitted: 3 October 2021 Revised: 19 December 2021 Accepted: 23 December 2021 Published: 15 February 2022
}

\begin{abstract}
Endometrial cancer (EC) survivors are increasing progressively. However, treating this disorder may detrimentally affect the pelvic organs, resulting in pelvic floor disorders (PFD): urinary incontinence, pelvic organ prolapse, and bowel dysfunction. The aim of this review is to investigate the prevalence of PFD in EC survivors following both surgical and nonsurgical treatments. The authors conducted a structured search in the following databases: MEDLINE, EMBASE, Global Health, The Cochrane Library, and Web of Science from inception until August 2021. The inclusion criteria were: (1) women with EC, (2) observational studies, (3) original data, (4) PFD result evaluation, and (5) the use of verified tools for the evaluation of PFD. The initial search found 590 articles for PFD and endometrial cancer. Only 10 of the studies were finally available for further analysis, including 1849 individuals with EC. In total, the incidence of UI increased from $7.6 \%$ to $20.8 \%$ after EC therapy. The incidence of stress and urge UI after treatment ranged from 23 to $74.3 \%$ and 20.8 to $71.4 \%$, respectively. The prevalence of POP was as high as $13.6 \%$ in 638 EC survivors. The prevalence of fecal incontinence was $21 \%$ in 732 EC survivors. In conclusion, PFDs are common after endometrial cancer treatment. The lack of comparative studies between the type of EC and the type of treatment limits further exploration of the differences in PFD frequency among EC survivors and the variety of EC treatments.
\end{abstract}

Keywords: Endometrial cancer (survivors); Pelvic floor disorders; Urinary incontinence; Stress-urge urinary incontinence; Overactive bladder; Fecal incontinence

\section{Introduction}

Endometrial cancer (EC) is the most common gynecologic malignancy with a progressively growing incidence over the last decade [1,2]. This can be attributed to the increasing prevalence of obesity, the predominant modifiable risk factor for EC development, along with a parallel increase in a wide cluster of other common risk factors such as diabetes, metabolic syndrome, and smoking $[3,4]$. In addition, reduced fertility rates and menopausal hormone use (especially estrogen plus progestin formulations) may play a key role [5]. Another potential factor could be the reduced hysterectomy rates for non-malignant disorders observed in the last few years, which may increase the burden of women that may develop EC [6]. Women with this tumor have a generally good prognosis, with a five-year survival rate of approximately 81 percent of participants [7]. EC tumors are mainly well-differentiated and they are confined to the endometrium [8], which predicts an even better five-year survival rate $(90 \%)$ [9].

All in all, the increase in EC prevalence along with improvements in treatment has led to a significant increase in EC survivors. In 2016, the number of EC survivors reached 755,000 , making them the second-largest group of female cancer survivors in the United States [10]. Given the abovementioned, improvements in the quality of life of these pa- tients should be of paramount clinical relevance, but this has not been extensively evaluated. When selecting treatment options, it is important to take into consideration both the treatment's morbidity and its impact on quality of life. A wide range of therapeutic modalities are employed in EC therapy, all of which have the potential to influence the pelvic organs and cause pelvic floor symptoms: urinary incontinence (UI), pelvic organ prolapse (POP), and bowel disfaction (BD), whether used alone or in combination. In women with EC, the real prevalence of pelvic floor disorders (PFD) is unclear. The influence of EC treatment on the incidence of PFD has not been fully explored, and it is probable that it is mentioned relatively seldom with patients. Despite this, PFDs are prevalent, especially in older women, and have a major negative impact on quality of life [11]. A full literature evaluation on rates of PFD in women who have had EC treatment has not yet been completed.

The aim of this review was to explore the prevalence of PFD in EC survivors after surgical and non-surgical therapies. 


\section{Materials and methods}

\subsection{Search strategy and selection criteria}

Following the Cochrane Handbook for Systematic Reviews of Interventions version 6.2 guidelines [12], we conducted a review of observational studies examining PFDs among EC survivors. For our purposes, we utilized the NCI definition of cancer survivor, which considers an individual a cancer survivor from the moment of diagnosis to the end of his or her life. A structured search of the following databases was performed by two of the authors (IT, TM): MEDLINE, EMBASE, Global Health, The Cochrane Library, and Web of Science from inception to August of 2021. The following MeSH and non-MeSH terms were used in combination: 'EC', 'PFD', 'POP', 'UI', 'stress urinary incontinence (SUI)', 'urge urinary incontinence (UUI)', overactive bladder (OB)', and 'fecal incontinence (FI)'. We also looked through the references of relevant articles to see if any publications on PFD had been published among EC survivors. Studies having outcomes other than PFD, as well as those that did not involve EC survivors, were omitted. All studies of any design, except Case reports, Case Series, Letters, Editorials, and Reviews were included. The population inclusion criteria were: (1) women diagnosed with EC, (2) observational studies, (3) original data collection, (4) PFD result evaluation, (5) the use of verified tools for the evaluation of PFD. We excluded pilot studies and studies of gynecologic cancer survivors that did not separately offer estimates for EC patients.

\subsection{Study selection, data extraction, and quality assessment}

Based on the specified qualifying criteria, two reviewers independently reviewed each paper by title and abstract. Two reviewers independently evaluated the full texts of qualifying papers for data extraction (IT, TM). Author, year of publication, study population, timing of PFD assessment, PFD assessed, PFD data collection method, number of patients included in final analyses, demographic characteristics (i.e., age, gender, and ethnicity), statistical analysis method, and outcomes were among the information extracted. Disagreements among the reviewers on research eligibility, data extraction, and quality assessment were addressed by consensus (Fig. 1).

\section{Results}

Our search revealed 590 references that assess PFD after an EC diagnosis. After removing 105 duplicates, we evaluated the titles and abstracts of 485 unique papers. Following an examination of the titles and abstracts, 51 publications were retrieved in their entirety [13-62], with 10 eventually qualifying for this study (Fig. 1) [13-22]. Most of the studies were retrospective cross-sectional, with the evaluation of PFD taking place at some point following the EC therapy; only 3 of them were prospective, and the overall quality of the studies was poor. All studies used English

\section{STUDY SELECTION STRATEGY}

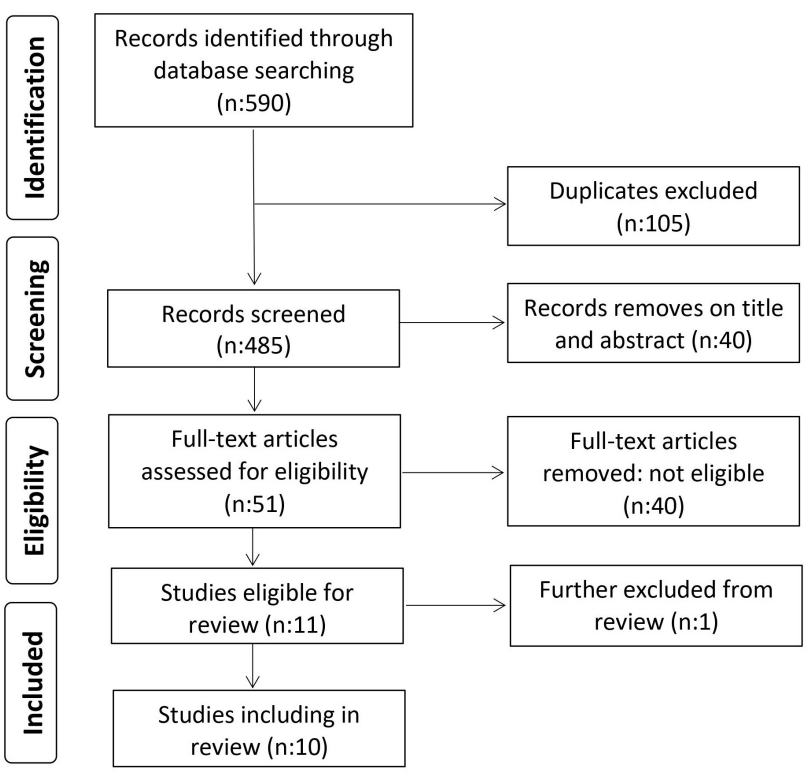

Fig. 1. The flow diagram of study search and selection.

as the language and were published in 2009 and afterwards.

Changes in PFD before and after therapy were reported only in 3 studies. Six studies exhibited PFD data only after EC therapy, and there was one study that presented the prevalence of PFD after EC diagnosis and before therapy. The impact of EC treatment on UI was evaluated in all the studies $(n=10)$; the impact of EC treatment on POP was evaluated in 4 studies; and the impact of EC treatment on FI was evaluated in 3 studies (Table 1, Ref. [13-22]). Treatment of endometrial malignancies may include various combinations of surgery, external beam radiotherapy, chemotherapy, and brachytherapy based on the extent of disease and other patient characteristics. Five of the studies focused on surgical therapy and four on drugs and radio therapy. The majority of articles comprised nonselected groups of EC patients, whereas 3 studies covered cases only in early stages (Stage I) (Table 1). The included studies' sample sizes ranged from 25 to 660 women with $\mathrm{EC}$, and the majority of them employed more than one PFD evaluation. PFDs were assessed mainly via the completion of validated questionnaires. Table 2 provides the list of validated questionnaires that were used in the studies to assess various PFDs. The most frequently utilized PFD questionnaire was the International Consultation on Incontinence Questionnaire-Female Lower Urinary Tract Symptoms (ICIQ-FLUTS).

Overall, our results elicit information from 1849 patients with EC. The prevalence of PFDs was investigated in 1320 patients prior to treatment, and PFDs were evaluated in 1581 EC survivors after treatment. The mean age of the patients was 62.9 years, and the mean body mass index (BMI) was $31.8 \mathrm{~kg} / \mathrm{m}^{2}$ [12-22]. 
Table 1. List of studies included in review. Evaluation of PFDs before and after endometrial cancer treatment.

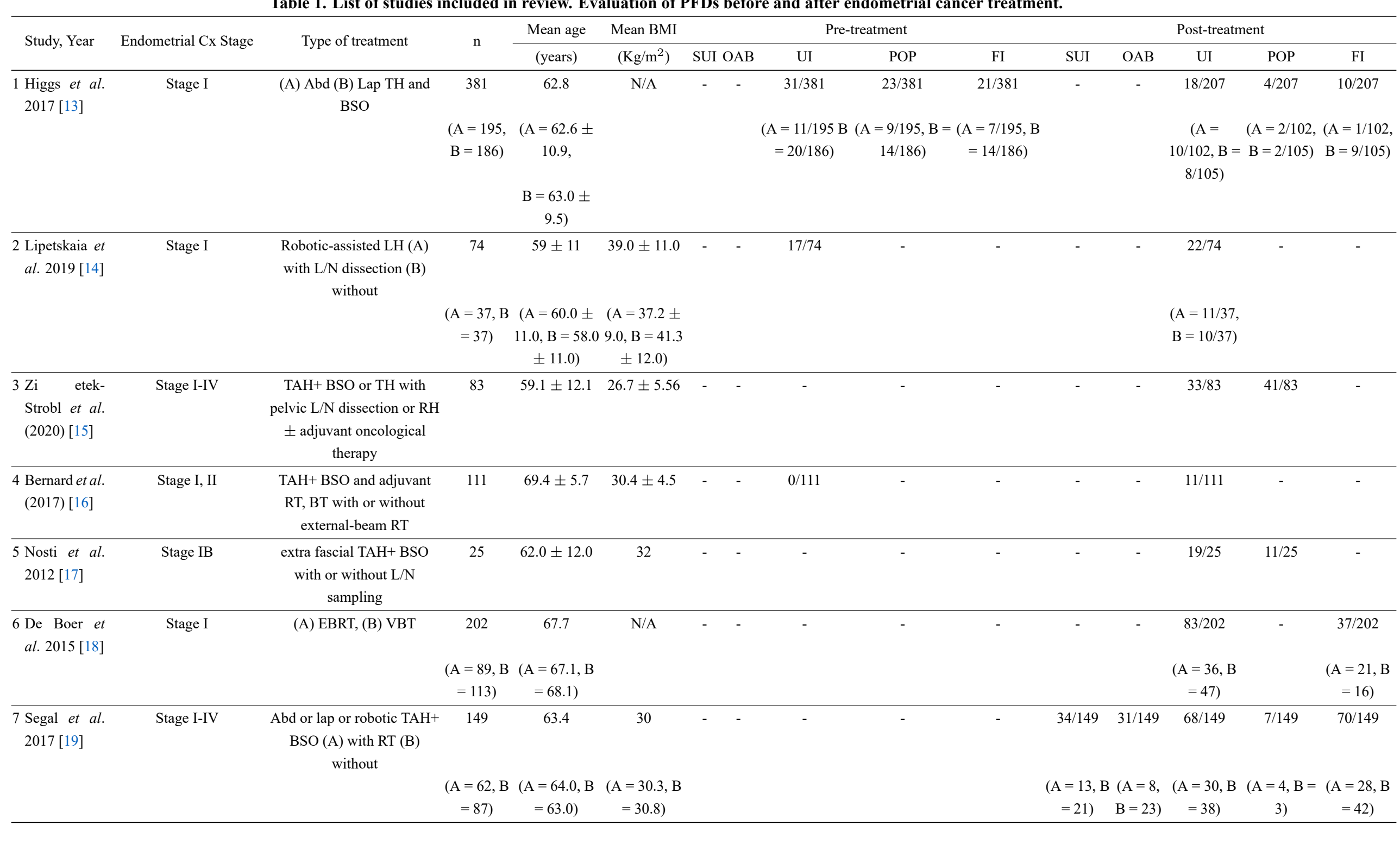


Table 1. Continued.

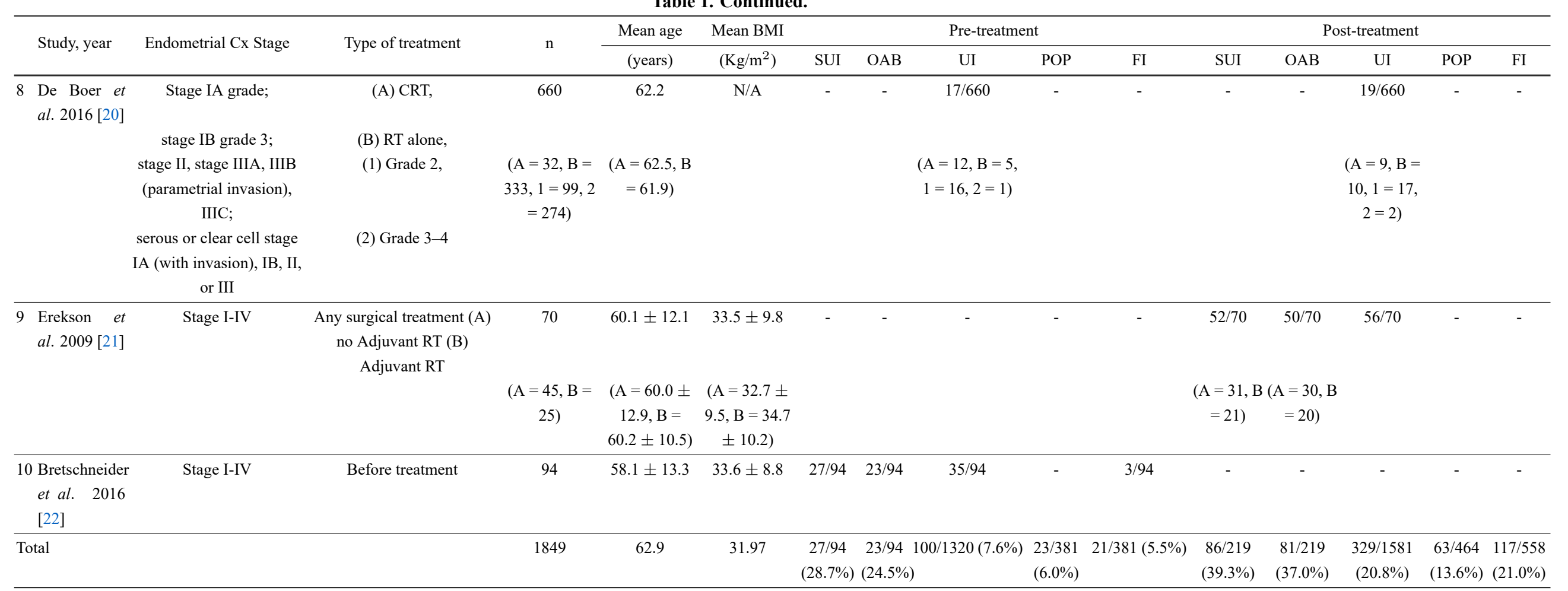

Cx, Cancer; Abd, abdominal; Lap, laparoscopic; TH, total hysterectomy; TAH, total abdominal hysterectomy; BSO, bilateral salpingectomy and oophorectomy; L/N, lymph node; RT, radiotherapy; VBT, vaginal brachytherapy; EBRT, external beam radiation therapy; CRT, chemoradiotherapy; RH, radical Wertheim-Meigs hysterectomy. 
Table 2. Questionnaires used in the assessment of patient-reported outcomes.

\begin{tabular}{|c|c|c|c|}
\hline Questionnaire & Abbreviation & Constructs measured & $\begin{array}{c}\text { Studies using } \\
\text { questionnaire } \mathrm{n}(\%)\end{array}$ \\
\hline $\begin{array}{l}\text { International Consultation on Incontinence Questionnaire-Female Lower Urinary } \\
\text { Tract Symptoms }\end{array}$ & ICIQ-FLUTS & Evaluating female lower urinary tract symptoms and impact on quality of life $(\mathrm{QoL})$ & $3(30)$ \\
\hline International Consultation on Incontinence Questionnaire - Urinary Incontinence & ICIQ-UI & $\begin{array}{l}\text { A questionnaire for evaluating the frequency, severity and impact on quality of life (QoL) of urinary } \\
\text { incontinence }\end{array}$ & $1(10)$ \\
\hline Pelvic Floor Distress Inventory-20 & PFDI-20 & $\begin{array}{l}\text { This Questionnaire will ask if there are certain bowel, bladder, or pelvic symptoms and how much } \\
\text { they bother over the last } 3 \text { months }\end{array}$ & $2(20)$ \\
\hline Pelvic Floor Impact Questionnaire & PFIQ-7 & It is a health-related quality of life questionnaire for women with pelvic floor conditions & $1(10)$ \\
\hline $\begin{array}{l}\text { European Organization for Research and Treatment of Cancer Quality of Life Ques- } \\
\text { tionnaire Core } 30\end{array}$ & EORTC QLQ-C30 & $\begin{array}{l}\text { Designed to measure cancer patients' physical, psychological and social functions. The question- } \\
\text { naire is composed of multi-item scales and single items }\end{array}$ & $1(10)$ \\
\hline Urinary Distress Inventory-6 & UDI-6 & assess symptom distress and the impact on daily life of urinary incontinence & $1(10)$ \\
\hline incontinence specific QoL using the Incontinence Impact Questionaire-7 & IIQ-7 & Refer to areas in your life that may have been influenced or changed by accidental urine loss & $1(10)$ \\
\hline Incontinence Severity Index questionnaire & ISI & $\begin{array}{l}\text { A questionnaire composed of a two-items which assess the frequency ( } 4 \text { levels) and amount ( } 3 \\
\text { levels) of urine leakage }\end{array}$ & $2(20)$ \\
\hline Questionnaire for Urinary Incontinence Diagnosis & QUID & A self-administered, 6-item questionnaire designed to distinguish between SUI and UUI & $1(10)$ \\
\hline International Consultation on Incontinence Questionnaire Vaginal Symptoms Module & ICIQ-VS & $\begin{array}{l}\text { A robust instrument for assessing a range of vaginal and sexual symptoms, in particular those of } \\
\text { pelvic organ prolapse. }\end{array}$ & $2(20)$ \\
\hline Pelvic Organ Prolapse/Urinary Incontinence Sexual questionnaire & PISQ-12 & $\begin{array}{l}\text { It is aimed at clinicians and other medical specialists that are interested to assess the sexual function } \\
\text { in women with urinary incontinence or pelvic organ prolapse. The score consists of } 12 \text { items, all } \\
\text { of which are questions pertaining to sexual life aspects. }\end{array}$ & $1(10)$ \\
\hline $\begin{array}{l}\text { International Consultation on Incontinence Questionnaire Anal Incontinence Symp- } \\
\text { toms and Quality of Life Module }\end{array}$ & ICIQ-B & $\begin{array}{l}\text { A patient-completed questionnaire for evaluating symptoms of anal incontinence (including flatus } \\
\text { incontinence) and impact on quality of life (QoL), provides a robust measure organized into three } \\
\text { domains, bowel pattern, bowel control and impact on quality of life associated with anal inconti- } \\
\text { nence symptoms. }\end{array}$ & $1(10)$ \\
\hline Fecal Incontinence Severity Index & FISI & $\begin{array}{l}\text { Quantify the impact of adult incontinence leakage on quality of life and describes the severity of } \\
\text { different types of incontinence for bowel contents }\end{array}$ & $1(10)$ \\
\hline Impact of Cancer version 2 & IOCv2 & $\begin{array}{l}\text { Designed to assess the physical and psychosocial health experience of cancer survivors through its } \\
\text { positive and negative impacts. }\end{array}$ & $1(10)$ \\
\hline
\end{tabular}


Table 3. Urinary incontinence evaluation before and after treatment of endometrial cancer.

\begin{tabular}{|c|c|c|c|c|c|c|c|c|c|}
\hline & \multirow{2}{*}{ Study, Year } & \multicolumn{5}{|c|}{ Pre-treatment } & \multicolumn{3}{|c|}{ Post-treatment } \\
\hline & & $\mathrm{n}$ & SUI & $\mathrm{OAB}$ & UI & $\mathrm{n}$ & SUI & $\mathrm{OAB}$ & UI \\
\hline 1 & Higgs et al., 2017 [13] & 381 & - & - & $31 / 381(8.1 \%)$ & 207 & - & - & $18 / 207(8.7 \%)$ \\
\hline 2 & Lipetskaia et al., 2019 [14] & 74 & - & - & $17 / 74(23.0 \%)$ & 74 & - & - & $22 / 74(29.7 \%)$ \\
\hline 3 & Zietek-Strobl et al., 2020 [15] & - & - & - & - & 83 & - & - & $33 / 83(39.7 \%)$ \\
\hline 4 & Bernard et al., 2017 [16] & 111 & - & - & $0 / 111(0.0 \%)$ & 111 & - & - & $11 / 111(9.9 \%)$ \\
\hline 5 & Nosti et al., 2012 [17] & - & - & - & - & 25 & - & - & $19 / 25(76.0 \%)$ \\
\hline 6 & De Boer et al., 2015 [18] & - & - & - & - & 202 & - & - & $83 / 202(41.1 \%)$ \\
\hline 7 & Segal et al., 2017 [19] & - & - & - & - & 149 & $34 / 149(22.8 \%)$ & $31 / 149(20.8 \%)$ & $68 / 149(45.6 \%)$ \\
\hline 8 & De Boer et al., 2016 [20] & 660 & - & - & $17 / 660(2.6 \%)$ & 660 & - & - & $19 / 660(2.9 \%)$ \\
\hline 9 & Erekson et al., 2009 [21] & - & - & - & - & 70 & $52 / 70(74.3 \%)$ & $50 / 70(71.4 \%)$ & $56 / 70(80.0 \%)$ \\
\hline \multicolumn{2}{|c|}{10 Bretschneider et al., 2016 [22] } & 94 & 27/94 (28.7\%) & 23/94 (24.5\%) & $35 / 94(37.2 \%)$ & - & - & - & - \\
\hline \multicolumn{2}{|c|}{ Total } & 1320 & 27/94 (28.7\%) & 23/94 (24.5\%) & $100 / 1320(7.6 \%)$ & 1581 & $86 / 219(39.3 \%)$ & $81 / 219(37.0 \%)$ & $329 / 1581(20.8 \%)$ \\
\hline
\end{tabular}

Table 4. Pelvic organ prolapse evaluation before and after endometrial cancer treatment.

\begin{tabular}{lcccccc}
\hline \multirow{2}{*}{ Study, Year } & \multicolumn{3}{c}{ Pre-treatment } & \multicolumn{2}{c}{ Post-treatment } \\
\cline { 3 - 7 } & & $\mathrm{n}$ & $\mathrm{n}$ & $\mathrm{POP}$ & $\mathrm{n}$ & POP \\
\hline 1 & Higgs et al., 2017 [13] & 381 & 381 & $21 / 381(5.5 \%)$ & 207 & $4 / 207(1.9 \%)$ \\
2 & Zietek-Strobl et al., 2020 [15] & 83 & - & - & 83 & $41 / 83(49.4 \%)$ \\
3 & Nosti et al., 2012 [17] & 25 & - & - & 25 & $11 / 25(44.0 \%)$ \\
4 & Segal et al., 2017 [19] & 149 & - & - & 149 & $7 / 149(47.0 \%)$ \\
Total & & 638 & 381 & $23 / 381(5.5 \%)$ & 464 & $63 / 464(13.6 \%)$ \\
\hline
\end{tabular}

\subsection{Urinary incontinence}

Urinary incontinence: Non-classified UI, SUI, and UUI were reported in all 10 studies. More specifically, all articles evaluated non-classified UI and only 3 assessed SUI and UUI. Pre-treatment UI rates ranged from 2.6 to $37.2 \%$. According to the study results, the incidence of non-classified UI increased after EC therapy from $8.3 \%$ to $20.8 \%$ ( $p<0.001)$. All studies indicate that the nonclassified UI rates increase after EC therapy; the prevalence of non-classified UI increases from $2.6-37.2 \%$ before to 2.9-80.0\% after EC treatment. However, the increase in the frequency of UI is not significant in all studies. Only in one study with 111 patients did the difference in UI significantly increase after EC treatment $(p<0.001)$ [16]; the other studies that included patients who had UI evaluation before and after EC treatment did not show a statistical difference (Table 3, Ref. [13-22]).

Stress and urge urinary incontinence: SUI and UUI were examined only in 3 studies, whereas there was no study to evaluate the prevalence of SUI or UUI both before and after EC therapy. According to data analysis from all 3 trials, the prevalence of SUI and UUI increased after EC treatment from $28.7 \%$ to $39.2 \%(p=0.07)$ and from $24.5 \%$ to $37.0 \%(p=0.03)$, respectively. There is a wide range of SUI and UUI incidence after oncological treatment in the included studies (SUI: 23.0-74.3\%, UUI: 20.8-71.4\%). However, these studies include a trial where SUI and UUI incidence of EC patients were recorded only before treat- ment $(n=94)$ [10], and two trials where SUI and UUI incidence of EC patients were recorded only after treatment ( $n$ =219) $[19,21]$ (Table 3$)$.

\subsection{Pelvic organ prolapse and Bowel dysfunction}

Pelvic organ prolapse: The prevalence of POP in 638 survivors of EC was evaluated in 4 studies (Table 4, Ref. $[13,15,17,19])$ and a prolapse rate of $13.6 \%$ was found after EC therapy $(p<0.001)[13,15,17,19]$. There was only one study that examined the POP before and after any oncology intervention, and a decrease in POP incidence after EC therapy from $6 \%$ to $2 \%$ was recorded $(p=0.038)$ [13].

Fecal incontinence: In three studies (732 patients) after EC therapy, the total rate of FI was $21 \%$. The FI rates ranged from $6.0 \%$ to $47 \%$, and there was a statistical increase in FI after EC treatment $(p<0.001)$ (Table 5) [13,18,19]. Higgs et al. (2017) found a baseline FI rate of $6 \%$ using the validated Pelvic Floor Distress Inventory (PFDI) and recorded a decrease of $1.2 \%$ after oncological therapy ( $p=0.54)$ [13]. Segal et al. (2017) [19] found an incontinence of liquid stool rate of $47 \%$ (the highest rate reported) in EC survivors using the Fecal Incontinence Severity Index (FISI) with a follow-up of 84-96 months.

\subsection{Surgery only treatment vs surgery plus radiotherapy with or without adjuvant chemotherapy}

After being diagnosed with EC, the vast majority of women are subjected to hysterectomy, with adjuvant radiation therapy being recommended for roughly $45 \%$ of these 
Table 5. Fecal incontinence evaluation before and after endometrial cancer treatment.

\begin{tabular}{lcccccc}
\hline \multirow{2}{*}{ Study, Year } & \multicolumn{3}{c}{ Pre-treatment } & \multicolumn{2}{c}{ Post-treatment } \\
\cline { 3 - 7 } & & $\mathrm{n}$ & $\mathrm{n}$ & $\mathrm{FI}$ & $\mathrm{n}$ & $\mathrm{FI}$ \\
\hline 1 & Higgs et al., 2017 [13] & 381 & 381 & $23 / 381(6.0 \%)$ & 207 & $10 / 207(4.8 \%)$ \\
2 & De Boer et al., 2015 [18] & 202 & - & - & 202 & $37 / 202(18.3 \%)$ \\
3 & Segal et al., 2017 [19] & 149 & - & - & 149 & $70 / 149(47.0 \%)$ \\
\multicolumn{2}{l}{ Total } & 732 & 381 & $23 / 381(6.0 \%)$ & 558 & $117 / 558(21.0 \%)$ \\
\hline
\end{tabular}

patients based on pathologic findings [63]. External beam radiotherapy, chemotherapy, and brachytherapy may alter the structure and function of pelvic organs such as the bladder, colon, and vagina and may increase the chance of developing pelvic floor problems.

Erekson et al. conducted a cross-sectional study with a 51-month follow-up to assess SUI and UUI in 70 patients following surgery and radiotherapy using the UDI questionnaire. SUI occurred in $69 \%$ of patients following surgery alone, and in $84 \%$ following surgery and radiation. UUI occurred in $67 \%$ of patients following surgery alone and in $80 \%$ of individuals following surgery and radiation. The mean UDI-6 and IIQ-7 scores for women who had adjuvant radiation therapy were higher than those who did not receive adjuvant radiation therapy [47 (26.8) vs. 35.6 (21.7); $p=0.05)]$ and [24.4 (28.5) vs. $8.1(16.4) ; p=0.004)]$. Adjuvant radiation therapy was related to worsening incontinence symptoms and a negative influence on QOL [21]. In the Saya Segal et al. (2017) study, 149 EC survivors were recruited, and radiation therapy was applied to $41 \%$ of these patients. The rates of UI in cancer survivors who were exposed and not exposed to radiation therapy were $48 \%$ and $58 \%$, respectively $(p=0.47)$ and there was no difference in the prevalence of FI across groups [19]. de Boer et al. in their multicenter randomized trial enrolled $427 \mathrm{pa}-$ tients and established the efficacy of vaginal brachytherapy for local disease control with fewer side effects than external beam radiotherapy in patients with high-intermediate risk disease. It also evaluated bowel and urinary symptoms more than 7 years after treatment with surgery and brachytherapy or surgery and external beam radiotherapy using cancer-specific health-related QOL questionnaires. UI rates in the brachytherapy and external beam radiotherapy groups were $41 \%$ and $44 \%$, respectively, among 196 survey respondents. Daytime frequency rates were $61 \%$ in both groups, but dysuria rates were slightly lower in the brachytherapy group than in the external beam radiotherapy group ( $6 \%$ and $9 \%$, respectively). The FI and FU rates were higher in patients who got external beam radiotherapy (24\% and $55 \%$, respectively) than in those who received brachytherapy ( $15 \%$ and $32 \%$, respectively) [18].

\section{Discussion}

The prevalence of PFD in survivors of EC after treatment is summarized in this review. Our findings show that all PFDs are very frequent in EC survivors. The incidence of UI ranges from 2.9-80.0\% (range of SUI: $22.8-74.3 \%$; range of UUI: 20.8-71.4\%). The incidence of POP ranges from $1.9-49.0 \%$. The incidence of FI ranges from $4.8-$ $47.0 \%$.

When comparing the findings of our study to the general population, the frequency of PFDs after treatment of EC appears to be increased. In the general population, the rate of UI ranges from $3.5 \%$ to $38.2 \%$, while that of FI ranges from $2.6 \%$ to $21 \%$ [64]. The frequency of UI in the general population is almost half compared to that of UI in our study. The frequency of FI (is even lower compared to that of FI in our study. According to our study, there is a statistically significant increase in the incidence of UI ( $p$ $<0.001)$, OAB $(p=0.03)$, POP $(p<0.001)$, and FI $(p<$ $0.001)$ in EC survivors after oncological treatment. However, due to (1) the methodology of this review, (2) the nondiscrimination of the stage and the type of EC, and (3) the non-discrimination of the type of EC treatment, our results are not solid. Nevertheless, this data serves as indirect evidence of the increased PFD frequency in EC patients after treatment.

While research on the prevalence of PFD after therapy predominates in the literature, it is critical to evaluate the baseline prevalence before the initiation of any treatment. The lack of pre-treatment data across all these studies appears to be the main problem with the investigation of the frequency of PFD in EC patients after treatment. Thus, the calculation of any post-treatment changes in the frequency of PFD compared to the baseline symptoms is practically impossible. Our review confirms this lack of data, and for this reason we included the study of Bretschneider et al. (2016) [22] as a baseline for future comparisons of pre- and post-treatment.

It appears that the incidence of PFD in EC survivors varies widely due to the variations in the applied methodology (i.e., different PFD questionnaires) measurements, the variations in the type of treatment, and the variations in the length of the follow-up. Moreover, the absence of research where there is direct comparison related to the type and stage of EC precludes further discussion of the variations in PFD prevalence between EC survivors and the subtypes of EC. The long-term follow-up of the randomized controlled PORTEC studies has provided some information on the occurrence of PFD in EC survivors. In particular, in the follow-up study to PORTEC-2 [20], a comparative study in which patients underwent surgery followed by ei- 
ther brachytherapy or radiotherapy, both treatment modalities were associated with high rates of urinary dysfunction, urinary frequency, and dyspareunia 84 months after treatment. Therefore, our data suggest that no conclusion about the relationship between the intensity of the PFDs and the type of EC can be elicited. As the kind of treatment method is determined by EC type and stage, many patients may receive numerous modalities of treatment, making it impossible to comment on the influence of individual treatment modalities on the development of PFDs. Moreover, there were many studies excluded from this review because the stated prevalence of PFD was not differentiated by gynecologic cancer type. Another important drawback is the absence of comparison research assessing the influence of various therapy modalities on PFDs.

Furthermore, there was little uniformity in the types of validated instruments utilized for objective PFD evaluation. Many of the excluded research utilized no validated questionnaires, raising concerns about the data's reliability and repeatability. The use of 14 different questionnaires in PFD research hinders the capacity to directly compare studies and findings. The ICIQ-FLUTS was the most frequently used questionnaire in the literature we evaluated. This instrument evaluates and quantifies lower urinary tract symptoms (LUTS) and their influence on quality of life. It comprises 12 LUTS-related questions split into three categories: filling (4 questions), voiding (3 questions), and incontinence (5 questions). The responses are based on LUTS experiences during the past four weeks. Furthermore, no included publication utilized clinical examination or urodynamic studies (UDS) to evaluate the PFD symptoms; the complete absence of clinical evaluation in all evaluated articles reduces the validity of the data gathered.

EC treatments seem to deteriorate pre-existing PFD or elicit new symptoms. The most common surgery performed on EC patients is abdominal hysterectomy with bilateral salpingo-ophorectomy. It is expanded, when necessary, by pelvic lymphadenectomy, paracolpium removal, or debulking surgery. This more invasive and severe surgery causes immediate intra-operative and early post-operative problems, as well as damage to surrounding tissues, and contributes to an increase in the likelihood of PFDs. The goal of radical pelvic surgery is to limit the recurrence of the cancer, but it may also harm urogenital nerves and blood vessels. Tissue hypoxia, scarring, and local ischemia can all raise the likelihood of PFD. Furthermore, the combination treatment (surgery plus radiation and chemoradiation) has a detrimental impact on the lower urinary tract and pelvic floor organs. The danger of problems following pelvic radiation is obvious, affecting not only the genitourinary system but also the gastrointestinal tract. Urgency, stress urine incontinence, interstitial cystitis, urinary bladder fibrosis, vaginal fibrosis, and vesico/urethro-vaginal fistulas are among the side effects that might affect patients immediately or for a long period following therapy [15].
This review's key strengths include an overall rigorous methodology, defined inclusion criteria, a thorough search of numerous databases, and duplicate assessments of titles/abstracts, full-text, and data to guarantee accuracy before qualitative analysis. Furthermore, the absence of reviews, and more specifically, better organized ones, that correlate EC treatment with PFD enhances the dynamics of this review. The main drawback, as with most evaluations, was the inadequacies of the examined literature. The research demographics, evaluation methods, and timing of survey administration all differed significantly. Moreover, the heterogeneity and the methodological discrepancies among the studies indicate that in the future only welldesigned studies should be conclusive. Finally, a potential problem with this type of research is the lack of clear clinical value of PFDs in the management of EC patients. It is true that PFDs do not change the EC treatment at all, and should be considered as a nearly separate entity, either induced by EC treatment or not. PFDs should be treated in the same manner as in healthy patients when the clinical status of EC survivors enables that. However, the possible increase in PFDs rates in EC patients may indicate that there may be treatments that induce the clinical burden of PFDs and that potential research could highlight the pathways for minimizing such influence.

In conclusion, PFDs are common in EC survivors and should be discussed with patients. The results of this review highlight a few suggestions for the forthcoming studies. The use of validated questionnaires is mandatory in order to determine baseline prevalence and the influence of particular oncologic therapy methods on PFD. Additional comparisons between EC survivors and the general population regarding PFDs are important in order to calculate the relevant PFD rates. Future research should focus on improving quality of life in EC survivors by using oncologic therapies that produce less pelvic floor injury and lead to a reduced incidence of PFD. Gynecology oncologists should consider screening for PFD at the time of EC diagnosis before starting therapy, and they should continue to evaluate PFD during treatment to identify the best time for intervention for control of the symptoms if clinically required. Early detection and identification of PFD in EC survivors would allow for comprehensive management, which might reduce morbidity from therapy and enhance quality of life.

\section{Author contributions}

IT, TM, DT and GFG designed the protocol. IT, TM, LZ, and GFG participate in project development. IT and TM performed the data collection. IT, TM, LZ, and DT analyzed the data. All authors contributed to editorial changes in the manuscript. All authors read and approved the final manuscript.

\section{Ethics approval and consent to participate}

Not applicable. 


\section{Acknowledgment}

We would like to acknowledge all those who helped me during the writing of this manuscript. Thanks to all the peer reviewers for their opinions and suggestions.

\section{Funding}

This research received no external funding.

\section{Conflict of interest}

The authors declare no conflict of interest.

\section{References}

[1] Siegel RL, Miller KD, Jemal A. Cancer statistics, 2015. CA: A Cancer Journal for Clinicians. 2015; 65: 5-29.

[2] Wartko P, Sherman ME, Yang HP, Felix AS, Brinton LA, Trabert $\mathrm{B}$. Recent changes in endometrial cancer trends among menopausal-age U.S. women. Cancer Epidemiology. 2013; 37: 374-377.

[3] Bhaskaran K, Douglas I, Forbes H, dos-Santos-Silva I, Leon DA, Smeeth L. Body-mass index and risk of 22 specific cancers: a population-based cohort study of $5 \cdot 24$ million UK adults. The Lancet. 2014; 384: 755-765.

[4] Mozumdar A, Liguori G. Persistent increase of prevalence of metabolic syndrome among U.S. adults: NHANES III to NHANES 1999-2006. Diabetes Care. 2011; 34: 216-219.

[5] Jamal A, Agaku IT, O'Connor E, King BA, Kenemer JB, Neff L. Current cigarette smoking among adults-United States, 20052013. Morbidity and Mortality Weekly Report. 2014; 63: 11081112.

[6] Wright JD, Herzog TJ, Tsui J, Ananth CV, Lewin SN, Lu Y, et al. Nationwide Trends in the Performance of Inpatient Hysterectomy in the United States. Obstetrics \& Gynecology. 2013; 122: 233-241.

[7] SEER. SEER Cancer Stat Facts: Endometrial Cancer. Bethesda, MD 2017. Available at: http://seer.cancer.gov/statfacts/html/cor p.html (Accessed: 19 December 2021).

[8] Münstedt K, Wagner M, Kullmer U, Hackethal A, Franke FE. Influence of body mass index on prognosis in gynecological malignancies. Cancer Causes \& Control. 2008; 19: 909-916.

[9] Creasman W, Odicino F, Maisonneuve P, Quinn M, Beller U, Benedet J, et al. Carcinoma of the corpus uteri. FIGO 26th annual report on the results of treatment in gynecological cancer. International Journal of Gynecology \& Obstetrics. 2006; 95 : S105-S143.

[10] Miller KD, Siegel RL, Lin CC, Mariotto AB, Kramer JL, Rowland $\mathrm{JH}$, et al. Cancer treatment and survivorship statistics, 2016. CA: A Cancer Journal for Clinicians. 2016; 66: 271-289.

[11] Rutledge TL, Heckman SR, Qualls C, Muller CY, Rogers RG. Pelvic floor disorders and sexual function in gynecologic cancer survivors: a cohort study. American Journal of Obstetrics and Gynecology. 2010; 203: 514.e1-514.e7.

[12] Schünemann HJ, Vist GE, Higgins JP, Santesso N, Deeks JJ, Glasziou $\mathrm{P}$, et al. Interpreting results and drawing conclusions. Cochrane Handbook for Systematic Reviews of Interventions (eds J.P. Higgins, J. Thomas, J. Chandler, M. Cumpston, T. Li, M.J. Page and V.A. Welch). 2019; 3: 403-431.

[13] Higgs P, Janda M, Asher R, Gebski V, Forder P, Obermair A. Pelvic floor functional outcomes after total abdominal versus total laparoscopic hysterectomy for endometrial cancer. American Journal of Obstetrics and Gynecology 2018; 218: 419.e1419.e14.

[14] Lipetskaia L, Sharma S, Johnson MS, Ostergard DR, Francis S. Urinary incontinence and quality of life in endometrial cancer patients after robotic-assisted laparoscopic hysterectomy with lymph node dissection. Journal of Obstetrics and Gynaecology. 2019; 39: 986-990.

[15] Ziętek-Strobl A, Futyma K, Kuna-Broniowska I, Wojtaś M, Rechberger T. Urogynaecological Symptoms among Oncological Survivors and Impact of Oncological Treatment on Pelvic Floor Disorders and Lower Urinary Tract Symptoms. A SixMonth Follow-Up Study. Journal of Clinical Medicine. 2020; 9: 2804.

[16] Bernard S, Moffet H, Plante M, Ouellet M, Leblond J, Dumoulin C. Pelvic-Floor Properties in Women Reporting Urinary Incontinence after Surgery and Radiotherapy for Endometrial Cancer. Physical Therapy. 2017; 97: 438-448.

[17] Nosti PA, McDermott CD, Schilder JM, Stehman FB, Woodman PJ. Symptoms of Pelvic Floor Disorders and Quality of Life Measures in Postoperative Patients with Endometrial Cancer. Clinical Ovarian and Other Gynecologic Cancer. 2012; 5: 27-30.

[18] de Boer SM, Nout RA, Jürgenliemk-Schulz IM, Jobsen JJ, Lutgens LCHW, van der Steen-Banasik EM, et al. Long-Term Impact of Endometrial Cancer Diagnosis and Treatment on HealthRelated Quality of Life and Cancer Survivorship: Results from the Randomized PORTEC-2 Trial. International Journal of Radiation Oncology, Biology, Physics. 2015; 93: 797-809.

[19] Segal S, John G, Sammel M, Andy UU, Chu C, Arya LA, et al. Urinary incontinence and other pelvic floor disorders after radiation therapy in endometrial cancer survivors. Maturitas. 2017; 105: 83-88.

[20] de Boer SM, Powell ME, Mileshkin L, Katsaros D, Bessette P, Haie-Meder C, et al. Toxicity and quality of life after adjuvant chemoradiotherapy versus radiotherapy alone for women with high-risk endometrial cancer (PORTEC-3): an open-label, multicentre, randomised, phase 3 trial. The Lancet Oncology. 2016; 17: 1114-1126.

[21] Erekson EA, Sung VW, DiSilvestro PA, Myers DL. Urinary symptoms and impact on quality of life in women after treatment for endometrial cancer. International urogynecology journal and Pelvic Floor Dysfunction. 2009; 20: 159-163.

[22] Bretschneider CE, Doll KM, Bensen JT, Gehrig PA, Wu JM, Geller EJ. Prevalence of pelvic floor disorders in women with suspected gynecological malignancy: a survey-based study. International Urogynecology Journal. 2016; 27: 1409-1414.

[23] Fitzsimmons D, Gilbert J, Howse F, Young T, Arrarras J, Brédart A, et al. A systematic review of the use and validation of health-related quality of life instruments in older cancer patients. European Journal of Cancer. 2009; 45: 19-32.

[24] Rajamanoharan S, Duncan T, Abu J. The well-being of women following total laparoscopic hysterectomy versus total abdominal hysterectomy for endometrial cancer. Gynecological Surgery. 2012; 9: 335-345.

[25] Becker M, Malafy T, Bossart M, Henne K, Gitsch G, Denschlag D. Quality of life and sexual functioning in endometrial cancer survivors. Gynecologic Oncology. 2011; 121: 169-173.

[26] Quick AM, Seamon LG, Abdel-Rasoul M, Salani R, Martin D. Sexual function after intracavitary vaginal brachytherapy for early-stage endometrial carcinoma. International Journal of Gynecological Cancer. 2012; 22: 703-708.

[27] Foerster R, Schnetzke L, Bruckner T, Arians N, Rief H, Debus J, et al. Prognostic factors for long-term quality of life after adjuvant radiotherapy in women with endometrial cancer. Strahlentherapie Und Onkologie. 2016; 192: 895-904.

[28] Smits A, Lopes A, Das N, Bekkers R, Galaal K. The impact of BMI on quality of life in obese endometrial cancer survivors: does size matter? Gynecologic Oncology. 2014; 132: 137-141.

[29] Karabuga H, Gultekin M, Tulunay G, Yuce K, Ayhan A, Yuce $\mathrm{D}$, et al. Assessing the Quality of Life in Patients with Endome- 
trial Cancer Treated with Adjuvant Radiotherapy. International Journal of Gynecological Cancer. 2015; 25: 1526-1533.

[30] Gao H, Xiao M, Bai H, Zhang Z. Sexual Function and Quality of Life among Patients with Endometrial Cancer after Surgery. International Journal of Gynecological Cancer. 2018; 27: 608612.

[31] Robinson KM, Christensen KB, Ottesen B, Krasnik A. Diagnostic delay, quality of life and patient satisfaction among women diagnosed with endometrial or ovarian cancer: a nationwide Danish study. Quality of Life Research. 2012; 21: 1519-1525.

[32] Angioli R, Plotti F, Cafà EV, Dugo N, Capriglione S, Terranova $\mathrm{C}$, et al. Quality of life in patients with endometrial cancer treated with or without systematic lymphadenectomy. European Journal of Obstetrics, Gynecology, and Reproductive Biology. 2013; 170: 539-543.

[33] White AJ, Reeve BB, Chen RC, Stover AM, Irwin DE. Urinary incontinence and health-related quality of life among older Americans with and without cancer: a cross-sectional study. BMC Cancer. 2013; 13: 377.

[34] Barber MD, Walters MD, Cundiff GW. Responsiveness of the Pelvic Floor Distress Inventory (PFDI) and Pelvic Floor Impact Questionnaire (PFIQ) in women undergoing vaginal surgery and pessary treatment for pelvic organ prolapse. American Journal of Obstetrics and Gynecology. 2006; 194: 1492-1498.

[35] Aerts L, Enzlin P, Verhaeghe J, Poppe W, Vergote I, Amant F. Sexual functioning in women after surgical treatment for endometrial cancer: a prospective controlled study. The Journal of Sexual Medicine. 2015; 12: 198-209.

[36] Nout RA, van de Poll-Franse LV, Lybeert MLM, WárlámRodenhuis CC, Jobsen JJ, Mens JWM, et al. Long-term outcome and quality of life of patients with endometrial carcinoma treated with or without pelvic radiotherapy in the post operative radiation therapy in endometrial carcinoma 1 (PORTEC-1) trial. Journal of Clinical Oncology. 2011; 29: 1692-1700.

[37] Ceccaroni M, Roviglione G, Spagnolo E, Casadio P, Clarizia R, Peiretti M, et al. Pelvic dysfunctions and quality of life after nerve-sparing radical hysterectomy: a multicenter comparative study. Anticancer Research. 2012; 32: 581-588.

[38] Rutledge TL, Heckman SR, Qualls C, Muller CY, Rogers RG. Pelvic floor disorders and sexual function in gynecologic cancer survivors: a cohort study. American Journal of Obstetrics and Gynecology. 2010; 203: 514.e1-514.e7.

[39] Thomas SG, Sato HRN, Glantz JC, Doyle PJ, Buchsbaum GM. Prevalence of symptomatic pelvic floor disorders among gynecologic oncology patients. Obstetrics and Gynecology. 2013; 122: 976-980.

[40] Manchana T, Prasartsakulchai C, Santingamkun A. Long-term lower urinary tract dysfunction after radical hysterectomy in patients with early postoperative voiding dysfunction. International Urogynecology Journal. 2010; 21: 95-101.

[41] Yeoh E, Sun WM, Russo A, Ibanez L, Horowitz M. A retrospective study of the effects of pelvic irradiation for gynecological cancer on anorectal function. International Journal of Radiation Oncology, Biology, Physics. 1996; 35: 1003-1010.

[42] Donovan KA, Boyington AR, Judson PL, Wyman JF. Bladder and bowel symptoms in cervical and endometrial cancer survivors. Psycho-Oncology. 2014; 23: 672-678.

[43] Brooks RA, Wright JD, Powell MA, Rader JS, Gao F, Mutch $\mathrm{DG}$, et al. Long-term assessment of bladder and bowel dysfunction after radical hysterectomy. Gynecologic Oncology. 2009; 114: 75-79.

[44] Plotti F, Zullo MA, Sansone M, Calcagno M, Bellati F, Angioli R, et al. Post radical hysterectomy urinary incontinence: a prospective study of transurethral bulking agents injection. Gynecologic Oncology. 2009; 112: 90-94.

[45] Bosch JLHR, Norton P, Jones JS. Should we screen for and treat lower urinary tract dysfunction after major pelvic surgery? ICIRS 2011. Neurourology and Urodynamics. 2012; 31: 327-329.

[46] Pisani C, Deantonio L, Surico D, Brambilla M, Galla A, Ferrara $\mathrm{E}$, et al. Quality of life in patients treated by adjuvant radiotherapy for endometrial and cervical cancers: correlation with dosevolume parameters. Clinical \& Translational Oncology. 2016; 18: 901-908.

[47] Mirabeau-Beale KL, Viswanathan AN. Quality of life (QOL) in women treated for gynecologic malignancies with radiation therapy: a literature review of patient-reported outcomes. Gynecologic Oncology. 2014; 134: 403-409.

[48] Vaz AF, Pinto-Neto AM, Conde DM, Costa-Paiva L, Morais SS, Esteves SB. Quality of life and acute toxicity of radiotherapy in women with gynecologic cancer: a prospective longitudinal study. Archives of Gynecology and Obstetrics. 2008; 278: 215223.

[49] Fang P, Tan KS, Grover S, McFadien MK, Troxel AB, Lin L. Psychosocial encounters correlates with higher patient-reported functional quality of life in gynaecological cancer patients receiving radiotherapy. Radiation Oncology. 2015; 10: 34.

[50] Stinesen Kollberg K, Waldenström A, Bergmark K, Dunberger $\mathrm{G}$, Rossander $\mathrm{A}$, Wilderäng $\mathrm{U}$, et al. Reduced vaginal elasticity, reduced lubrication, and deep and superficial dyspareunia in irradiated gynecological cancer survivors. Acta Oncologica. 2015; 54: 772-779.

[51] Soisson S, Ganz PA, Gaffney D, Rowe K, Snyder J, Wan Y, et $a l$. Long-term, adverse genitourinary outcomes among endometrial cancer survivors in a large, population-based cohort study. Gynecologic Oncology. 2018; 148: 499-506.

[52] Creutzberg CL, van Putten WL, Koper PC, Lybeert ML, Jobsen JJ, Wárlám-Rodenhuis CC, et al. The morbidity of treatment for patients with Stage i endometrial cancer: results from a randomized trial. International Journal of Radiation Oncology, Biology, Physics. 2002; 51: 1246-1255.

[53] Lind H, Waldenström A, Dunberger G, al-Abany M, Alevronta $\mathrm{E}$, Johansson $\mathrm{K}$, et al. Late symptoms in long-term gynaecological cancer survivors after radiation therapy: a population-based cohort study. British Journal of Cancer. 2011; 105: 737-745.

[54] Sorbe BG, Horvath G, Andersson H, Boman K, Lundgren C, Pettersson $B$. External pelvic and vaginal irradiation versus vaginal irradiation alone as postoperative therapy in medium-risk endometrial carcinoma: a prospective, randomized study-qualityof-life analysis. International Journal of Gynecological Cancer. 2012; 22: 1281-1288.

[55] Herwig R, Bruns F, Strasser H, Pinggera GM, Micke O, Rehder $\mathrm{P}$, et al. Late urologic effects after adjuvant irradiation in stage $\mathrm{i}$ endometrial carcinoma. Urology. 2004; 63: 354-358.

[56] Onsrud M, Cvancarova M, Hellebust TP, Tropé CG, Kristensen GB, Lindemann K. Long-Term Outcomes after Pelvic Radiation for Early-Stage Endometrial Cancer. Journal of Clinical Oncology. 2013; 31: 3951-3956.

[57] Del Priore G, Taylor SY, Esdaile BA, Masch R, Martas Y, Wirth J. Urinary incontinence in gynecological oncology patients. International Journal of Gynecological Cancer. 2005; 15: 911914.

[58] Kadar N, Saliba N, Nelson JH. The frequency, causes and prevention of severe urinary dysfunction after radical hysterectomy. British Journal of Obstetrics and Gynaecology. 1983; 90: 858863.

[59] Skjeldestad FE, Hagen B. Long-term consequences of gynecologic cancer treatment on urinary incontinence: a populationbased cross sectional study. Acta Obstetricia et Gynecologica Scandinavica. 2008; 87: 469-475.

[60] Hall E, Robison K, Wohlrab K. Pelvic floor disorders in women with gynecologic malignancy. Current Opinion in Obstetrics \& Gynecology. 2018; 30: 446-450. 
[61] Doyle PJ, Thomas SG, Buchsbaum GM. Barriers to urogynecological care in a population of gynecological oncology patients. International Urogynecology Journal. 2018; 28: 913-916.

[62] Hazewinkel M, Sprangers M, Taminiau-Bloem E, van der Velden J, Burger M, Roovers J. Reasons for not seeking medical help for severe pelvic floor symptoms: a qualitative study in survivors of gynaecological cancer. British Journal of Obstetrics and Gynaecology. 2010; 117: 39-46.
[63] Delaney G, Jacob S, Barton M. Estimation of an optimal radiotherapy utilization rate for gynecologic carcinoma: part IIcarcinoma of the endometrium. Cancer. 2004; 101: 682-692.

[64] Wu JM, Vaughan CP, Goode PS, Redden DT, Burgio KL, Richter HE, et al. Prevalence and Trends of Symptomatic Pelvic Floor Disorders in U.S. Women. Obstetrics \& Gynecology. 2014; 123: 141-148. 